rising waters, and have again a richer growth of plants and of creatures great and small to feed on them and one another.

A hundred years ago, Johannes Müller was using the first tow-net, about the time when Edward Forbes was borrowing for the first time a fisherman's oyster-dredge; but only now do we begin to understand properly the importance of the floating life of the sea. Its distribution, its seasonal abundance, its variation with temperature, its presence in this water and absence in that, the vast variety of organisms of which it is variously and with varying importance composed, all these things are a great part of the science of the sea and of our understanding of all the fisheries. Prof. A. C. Hardy of Hull (a most ingenious student of the plankton) and Mr. E. R. Gunther have written an interesting report on the ways and means by which plankton is dispersed and distributed, and how the gathering-places of the whales may be expressed in terms of plankton, and again of the phosphate supply. Dr. N. A. Mackintosh has demonstrated a seasonal circulation in the Antarctic plankton on a scale unrivalled elsewhere; the big Euphausias, staple food of the Blue whale, first made known by the Challenger and met with again by Dundee whalers who went far south unsuccessfully some forty years ago, are fully described by Dr. F. C. Fraser and Mr. Dilwyn John. But without saying more of the ship's company and their doings, let me just say that the Discovery $I I$, with a great task to do and ample means to help to do it, has added largely and handsomely to natural knowledge, and given the ship's name an honourable place among voyages of exploration and discovery. There is one omission in the report before us. I have read it all through without encountering the name (save in a list of papers) of the leader and director of the Expedition, the distinguished author of the report.

I. W. T.

\title{
Tests in Common Use for the Diagnosis of Colour Defect*
}

\section{By Dr. Mary Collins}

$\mathrm{T}$ ESTS for colour vision fall into two categories. In one type of test, transmitted light is used, in the other reflected light. While the former type of test is regarded as the more fundamental, the latter can be of great service for quick diagnosis of colour anomaly. Colour tests may be administered purely for theoretical purposes, or they may be applied for practical purposes, as selection tests for different vocations. This second function assumes its most important role in vocations in which lack of accurate discrimination between different coloured signals may involve human lives. This function is also of significance in other vocations in which the lack of colour discrimination, though not involving danger to the community, is highly disadvantageous to its possessor.

There seems to be no need at the present day to emphasize the importance of the recognition and detection of colour defect. It is, however, very illuminating to study some of the more recent investigations in the field, particularly those concerned with the incidence of red-green defect. The percentages given seem to be much higher than in the reports of the earlier investigations. It does not necessarily follow that the incidence of the defect is increasing; the indications are rather that detection is more accurate owing to the

* From the presidential address to Section $J$ (Psychology) of the British Association, delivered at Nottingham on September 3. improvement of the test material. Out of 360 candidates applying for acceptance as apprentice printers, the percentage of red-green colour-blinds was $7 \cdot 5$, this figure being exclusive of the colour. weak and the anomalous.

It seems more or less agreed that red-green colour-blindness is a reduction system of normal colour vision, one cogent argument in support of this contention being that normal colour matches are valid for any type of dichromate. The colourblinds lack something which the normal eye has, but have nothing which the normal eye does not possess. The individual with normal colour vision sees a spectrum composed of six or seven colours. The red-green colour-blind has a spectrum composed of only two colours, these two colours being yellow and blue. The acceptance of this fact was delayed for a long time, and it is doubtful if it is yet generally accepted. Herschel, in 1845, was the first to put forward the dichromic explanation of colour-blindness. He pointed out in his article on "Light" in the "Encyclopædia Metropolitana" that certain individuals could only distinguish two oolours, and that these two colours were vellow and blue. Clerk Maxwell, among others, opposed this, for he accepted the theory put forward at that time by Young and Helmholtz that colour. blinds were either red-blind, green-blind or violetblind, and that the red-blind were blind to red, 
but could see the remaining two colours, green and violet: the green-blind were blind to green, but could see red and violet.

In an account by Pole of his own case, we find he vigorously protests against these prevailing beliefs, and gives a careful analysis of his own colour vision as evidence. $\mathrm{He}$ had been pronounced red-blind by Maxwell and green-blind by Holmgren. Pole repudiated both suggestions, and claimed that the true solution was that he was blind to both colours. This conclusion was confirmed by a large number of facts. One was the evidence of the colour-blinds themselves who, whether they were classified as red-blind or greenblind, asserted that their colour sense was composed of blue and yellow. Another was a case of congenital unilateral dichromatism investigated by von Hippel in 1880. The individual tested had normal colour vision in his left eye but was colourblind in his right eye. With the right eye he confused red and green with yellow, as tested by various standard tests. The colours which the subject could distinguish with his right eye were blue and yellow, these being confirmed when he looked at them with his normal eye. Von Hippel diagnosed the case as one of red-green blindness with spectrum of normal length. Holmgren examined the case with his wool test and proclaimed it to be one of red-blindness with shortened spectrum in accordance with the Helmholtz theory. Von Hippel retested his subject and reaffirmed his finding. This was the first case of monocular colour vision reported, and it undoubtedly strengthened the case for the acceptance of Herschel's and Pole's views. Holmgren, it is interesting to note, ultimately agreed that blue and yellow were the only colours seen. That this point is still controversial may be gathered from the statement made by Pitt in a recent investigation, that the fundamental responses of the protanope are blue and a saturated green, while those of the deuteranope are blue and a mixture of red and green.

Only a few cases of unilateral colour-blindness have been recorded, and these, according to Parsons, are of "doubtful value". In these cases, however, the suggestion is always that the colours seen are blue and yellow. Miles and Beaumont, who tested the two eyes separately in an investigation into colour-blindness, found considerable difference between the two eyes in many cases, and suggest that although there is no conclusive evidence as to the frequency of unilateral colourblindness, "possibly it amounts to three or four per cent of the colour-blind". They discovered one such case in a group of 23, and Miles and Craig found another in a group of 390 mercantile salesmen. This latter individual was a dry goods salesman and aware of his condition, and if required to match fabrics he closed the defective eye and made the proper discrimination with his normal eye. If these cases of unilateral colourblindness are as numerous as suggested, a field seems opened up for further investigation which may lead to definite conclusions as regards the fundamental sensations of the red-green colourblind.

The results of investigations carried out over a number of years at Edinburgh into the coloursensations of the red-green colour-blind seem to indicate that their colour sensations are indeed blue and yellow. The extent to which these two colours replace all the other colours in the spectrum is, however, not constant for every colour-blind. With some, yellow and blue may replace all the other colours, that is, red, orange, yellow and green may be seen as different shades of yellow, blue and violet as different shades of blue. Sometimes, instead of the green being replaced by yellow, it may appear as grey, or the blue-green may appear as grey, the extent of the neutral band varying with the gravity of the defect. A second neutral band is also found extra-spectrally in the complementary colour, in the purples. In one extreme case which came under observation, only two narrow bands of yellow and blue existed, the other colours being seen as shades of grey. Red appeared as black, orange as dark grey, yellow could be discriminated, green and bluegreen were seen as grey, blue could be distinguished, but violet appeared as dark grey. In one test, out of 76 colours observed, 64 of them appeared as grey.

All cases, however, are not so extreme as the one just described, and the general finding which seems to be gradually gaining ground is that there exist different degrees of colour-blindness extending from extreme cases in which blue and yellow are the only two colours visible, to milder cases in which the blindness to red and green is not total. In these milder cases the individual can see red and green if they are bright enough or vivid enough. It is these milder forms which constitute the great practical problem, for in these cases the ability to distinguish between red and green is likely to fail when the individuals are fatigued, or when the illumination is poor, as in mist or fog. The extreme cases can be easily detected, but the milder cases, which have been described as 'dangerous colour-blinds', require very careful examination if they are to be detected.

That different degrees of colour-blindness exist has been emphasized by more than one writer. Hayes "wonders if we shall presently have to give up all classifications by types, arrange colour defectives in distribution tables and give a colour graph or profile for each subject, showing his 
efficiency or deficiency for each colour in terms of a per cent of the normal or average attainment". Troland states that the original restriction of colour-blinds to protanopes, deuteranopes and tritanopes is no longer adequate, and allowances must now be made for more types of variation. Edridge-Green recognizes seven different types of colour vision, and Schjelderup states that there are at least eighteen significant species of colourblindness. Colling reaches the conclusion that it is quite unprofitable to try to classify the colour systems of the colour-blind because there exist so many individual variations.

One group in which the colour defect is not extreme has been definitely recognized. Seebeck, in 1837, found certain cases which he was reluctant to classify as colour-blinds, who yet showed signs of colour abnormality. It was not until 1881, however, that these cases were understood. In that year, Rayleigh found that a number of individuals with otherwise normal colour vision were unequally sensitive to red and green. In equating red (lithium line $670.8 \mu \mu$ ) and green (thallium line $535 \mu \mu$ ) to match a yellow (sodium line $589 \mu \mu$ ), since known as the Rayleigh equation, some were found to require far more red than the normal, others required an excess of green. Von Kries, in describing an extensive series of experiments, applied the name 'anomalous trichromates' to these cases, and this designation has gained universal currency. Guttman advocated the terms red-weak and green-weak, and distinguished seven characteristics which they manifest, the chief of which are high thresholds, heightened colour contrast and a quick fatigue to colour stimuli.

It is customary to divide these anomalous trichromates into two groups corresponding to the two groups of dichromates, deuteranomalous trichromates or partial deuteranopes in which the sensitivity to green is below normal, and protanomalous trichromates or partial protanopes in which the sensitivity to red is below normal. The green anomalous seem to be more numerous than the red anomalous, the ratio being quoted as 5 to $l$.

These cases, it may be, form the connecting link between normal colour vision on one hand and colour defect on the other, and if a sufficient number of eases could be tested ranging from normality to complete red-green deficiency, a continuous series might be obtained.

It is a moot point as to whether these anomalous trichromates form 'dangerous colour-blinds'. The general finding seems to be in favour of the affirmative. Some writers, for example, Troland, actually include them in classifications of types of colour-blindness. Oblath points out that they can only recognize colours when they are saturated and of intense luminosity ; "It is evident that these peculiaritios render these subjects less fitted for certain services". In a report on "Colour Vision Requirements in the Royal Navy" (Med. Res. Council Report, Spec. Series No. 185; 1933), it is stated that "the mildly anomalous trichromate can be considered a safe look-out. On the other hand, the unfit anomalous trichromate is, in many ways, a greater source of danger than the dichro. mate". The incidence of this anomaly is estimated, in the same report, as 6 per cent, which is stated to be a very conservative estimate. Both reports emphasize very strongly the fact that the anomalous trichromate behaves as if colour-blind when conditions are unfavourable, such as when mist, fog or smoke are present, and this is all the more disastrous because the individual is rarely aware that he suffers from any colour defect. The heightened contrast and the quick fatigue char. acteristic of such anomaly may well make the judgment of colour and the discrimination of colour highly erroneous. The testing and discovering of these cases of anomalous trichromatic vision is not easy, and necessitates very careful procedure, and generally not the application of one test, but of a battery of tests.

(To be continued.)

\section{Obituary Notices}

Sir David Orme Masson, K.B.E., F.R.S. PROF. SIR DAVID ORME MASSON, who died at 1 Melbourne on August 10, was born at Hampstead, London, on January 13, 1858. He was of mixed English and Scots descent. His father, Prof. David Masson, editor of Milton, Goldsmith and De Quincey, and Historiographer-Royal for Scotland, came of Aberdcenshire stock-there is a saying in the Don valley that "Eassons, Massons an' Kessons a' cam' frae Tarlandside". His mother, Rosaline Orme, had a forbear (Yeorge Rutt, the father of
Joseph Priestley's biographer, John Towill Rutt; and it may be mentioned, as throwing some light on the family, that the home of the Ormes, in Avenue Road, Hampstead, was a favourite rallying ground of the Pre-Raphaelites. In 1865 David Masson migrated from the chair of English literature at University College, London, to the Regius chair of English in the University of Edinburgh, and so it came about that his son, David Orme Masson, was educated at Edinburgh Academy and afterwards graduated M.A. and B.Sc. at Edinburgh. 